\title{
Analysis of the evolution of pollution indicators in a crossroads area of Sibiu, Romania
}

\author{
Lucian Tarnu, Alina Gligor and Cristian Deac* \\ Lucian Blaga University of Sibiu, Romania, Department of Industrial Engineering and Management, \\ Emil Cioran str., 4, Sibiu, Romania
}

\begin{abstract}
Starting from a new study on carbon monoxide and noise pollution levels in an important crossroads area of the city of Sibiu, Romania, the current paper uses the data to compare with data obtained during past studies carried out on the same area, allowing an assessment of the evolution of the two pollution indicators over time. The recent study, carried out over a two-week period in November 2017 both during the peak morning hours and at midday, combined a video-based vehicle count with measurements of the carbon monoxide and of the noise level, respectively. The data comparison reveals not only a worsening of the pollution levels in the centre of Sibiu over the past few years and should allow the determining of the best methods and means for reducing the level of the pollutants, possibly in correlation with the improvement of the road traffic conditions.
\end{abstract}

\section{Introduction}

Nowadays, pollution - and the associated risk for human health - is one of the most important problems in larger human settlements. While traditionally pollution has been blamed especially on the industrial units located within city/town limits, the pollution caused by transportation means - and foremost by road traffic - is certainly becoming a significant factor that needs to be taken into account by local administrations and city planners.

Road traffic pollution can manifest itself chiefly in two directions: pollution through noxious gaseous emissions and noise pollution. The most affected areas are those near the main roads and especially near crossroads, but due to the close-packed nature of habitation in urban areas, every part of a city is affected to a larger or lesser degree.

The city of Sibiu, located in central Romania, currently has a population of around 150000 permanent inhabitants, to which there needs to be added a significant temporary population - tourists, businessmen, workers etc. - attracted by the importance of the city as an industrial and commercial centre, with a rich history and culture. This leads to an increasing pressure on the road structure of the city and implicitly to an increasing level of pollution, thus to an increasing level of discomfort for the local residents.

While previously there have been studies carried out by various authors concerning the pollution levels in Sibiu, in some cases associated with recommendations for changes in terms of infrastructure, in the current paper, the authors not only analyse the traffic and pollution conditions in a key area from the central part of Sibiu, Romania but also compare

${ }^{*}$ Corresponding author: cristian.deac@ulbsibiu.ro 
this with studies carried out in the previous years, so that it is possible to analyse the evolution of pollution, on the one hand in terms of the emission of carbon monoxide and on the other hand in terms of noise pollution.

\section{The analysed area, means and method}

The area chosen by the authors for their research is the area of the Unirii square in the centre of Sibiu, an important and very busy crossroads area, where the north-south road traffic intersects with the east-west road traffic through the city (Figure 1 and Figure 2).

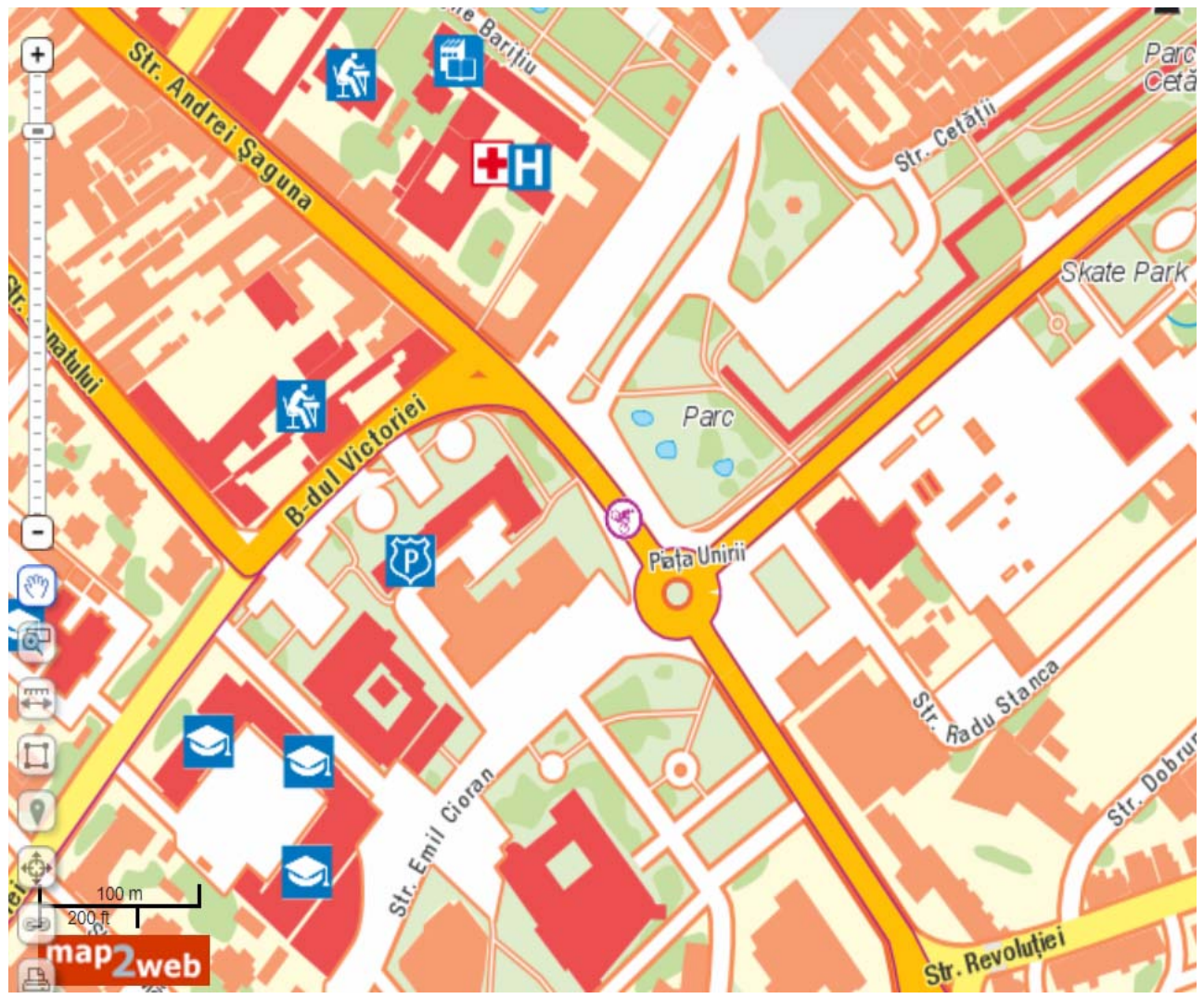

Fig. 1. Map of the area around the Unirii square and crossroads in central Sibiu, targeted by the present study [1].

This is an area of outstanding economical and administrative interest for the city, as it is located close to the city's historical centre and in or near to it there are important institutions such as banks, hotels, shopping centres, the local Police headquarters, a hospital, but also residential areas. The main roads passing through it connect several neighbourhoods of the city, but also funnel the traffic from and towards the exits from the city and towards the surrounding cities.

The crossroads' geometry seems to be well organised, but during peak hours the traffic capacity is visibly surpassed and there is an excessive level of noxious gas emissions and a high level of noise.

The analysis seeks to determine the current traffic and noise pollution conditions and to compare the results with results of previous studies carried out in the past in the same area. 


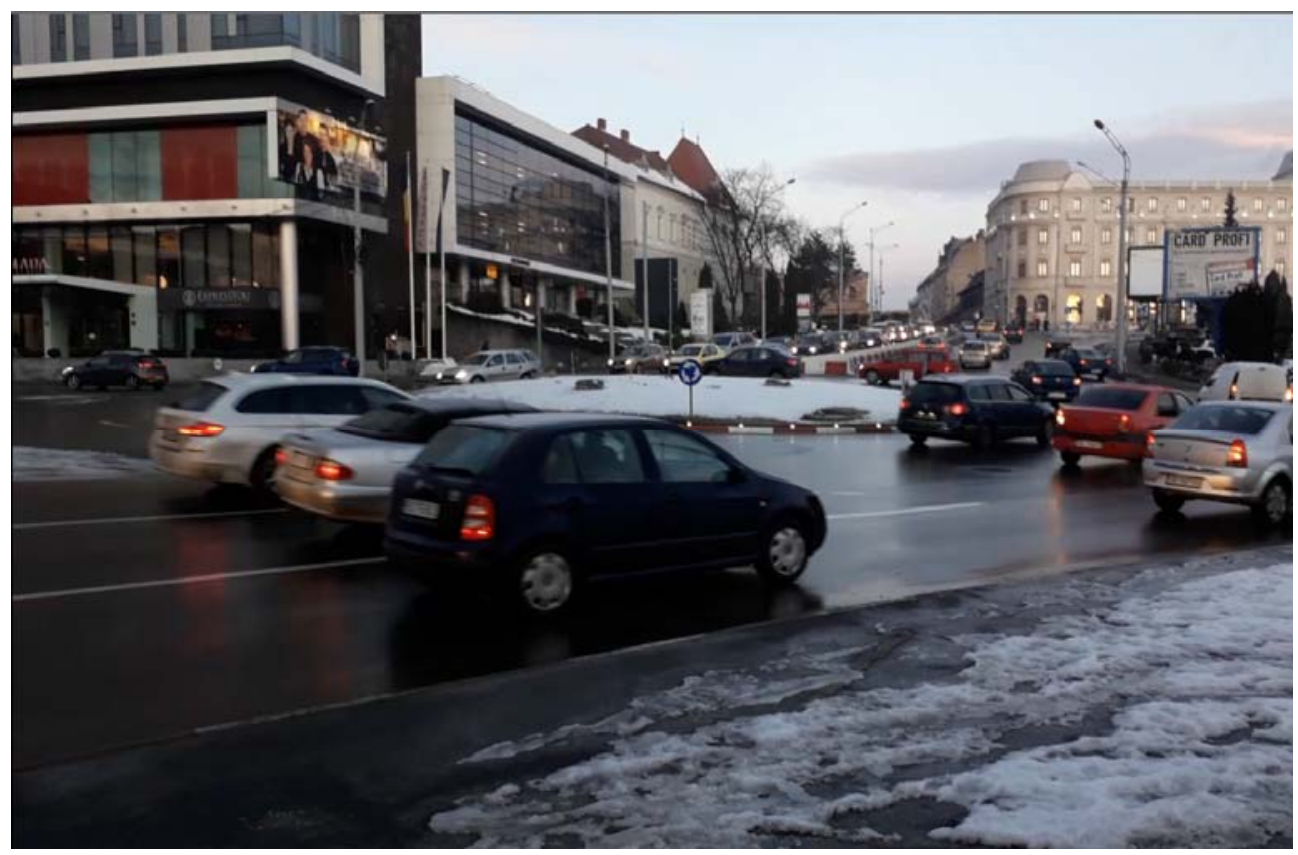

Fig. 2. Traffic conditions in the Unirii crossroads area at 8:00 a.m, November $24^{\text {th }}, 2017$.

The main activities that were carried out for this study included:

- analysis of the studied area (geometry, access, planned changes)

- collection of data regarding the traffic conditions

- simultaneously, collection of data regarding the carbon monoxide and noise pollution conditions.

- comparison of the pollution data with data from other studies and with relevant national standards.

The data regarding traffic conditions can be collected using one of the following methods $[2,3]$ :

- manual collection using a team of human observers

- analysis of video recordings

- collection using specialised equipment (sensors, GPS etc.).

When assessing the collected data, there needed to be taken into account also factors such as the meteorological conditions, the traffic intensity and the traffic's complexity.

The meterorological conditions varied during the study period - there were both sunny, warm days especially at the beginning of the study, rainy days and days with fog and snow, especially towards the end of the study period.

The current analysis started from video recordings of the crossroads (and of the vehicles passing through it from and towards different directions). There were three video recording points, chosen so that they covered all directions, even with some overlapping to allow crosschecking. Recordings (and the measurements of noxious emissions and of the noise level) were made over a period of two weeks, from November 6th, 2017 to November 24th, 2017 on every Monday, Wednesday and Friday during this period. Since the analysed speciality literature $[4,5,6]$, indicated that it is also important to select appropriate time periods for the counting, the analyses were carried out both during the peak morning hours (from 07:30 a.m. to 8:30 a.m.) and during a "calmer" midday period, for reference (from 12:00 p.m. to 1:00 p.m.).

The recordings were then reviewed and the vehicles were counted manually. 
Because the traffic flow through the crossroads contained different types of vehicles (small cars, motorcycles, trucks, buses etc.) that act differently in traffic, the authors have applied the coefficients indicated in the standard SR 7348-2001 [6] for obtaining equivalent vehicle numbers, using formula (1).

$$
N_{\text {equiv }}=N_{1} c_{1}+N_{2} c_{2}+\ldots+N_{i} c_{i}
$$

Where:

$\mathrm{N}_{\text {equiv }}$ - number of equivalent vehicles for the considered traffic flow and time period;

$\mathrm{N}_{1}, \mathrm{~N}_{2}, \ldots, \mathrm{N}_{\mathrm{i}}$ - number of vehicles of a certain type in the flow;

$\mathrm{c}_{1}, \mathrm{c}_{2}, \ldots, \mathrm{c}_{\mathrm{i}}-$ correction coefficients corresponding to each type of vehicle. For example, for cars, $\mathrm{c}=1$, for motorcycles $\mathrm{c}=0.5$ and for buses $\mathrm{c}=3.5$.

Also in order to allow a direct comparison with past data, the noxious emissions were analysed, simultaneously with the video recordings of the road traffic, only in terms of the carbon monoxide (CO) concentration. This was done using a Dräger PAC III device connected to a laptop via a data acquisition device NI 6808, instruments from the endowment of the Faculty of Engineering of the "Lucian Blaga" University of Sibiu, Romania. The main characteristics of the Dräger PAC III are as follows:

- $\quad$ single-gas detector, with exchangeable sensor for a variety of gases;

- continuous operating temperatures: -20 to $+50{ }^{\circ} \mathrm{C}$;

- weight: $200 \mathrm{~g}$.

Furthermore, the noise level in the crossroads was determined for the same time ranges, using a sound level meter model 2100 made by Quest Technologies, also from the endowment of the Faculty of Engineering of the "Lucian Blaga" University of Sibiu, Romania. The sound level meter can operate in three ranges: $30-70 \mathrm{~dB}, 50-120 \mathrm{~dB}$ and $70-140 \mathrm{~dB}$, respectively, with a precision of $0.1 \mathrm{~dB}$. The sound level meter was equipped with a band-pass filter in order to facilitate a clear signal and to eliminate possible disturbance factors.

The data obtained during this study were compared with data obtained by Borza et al. in 2012 [7, 8], by Inta et al in 2013 [9], and by Deac et al. in $2016[10,11]$.

\section{Results and discussion}

The analysis of the video recordings of the traffic has led, after applying the equivalation formula (1) to the data presented in Table 1, for all branches of the studied crossroads. The data in Table 1 are actually arithmetic means of the number of cars recorded for the 6 days of the study indicated above. This allows on the one hand to avoid an overload of data in the table, but also leads to statistically meaningful results.

The number of equivalent vehicles indicated in Table 1 was determined by applying equation 1 to each particular vehicle flow (as resulted from the video-based count) on a street and in a certain direction.

Table 1. Number of vehicles determined for all branches of the studied crossroads.

\begin{tabular}{|c|c|c|c|c|c|c|c|c|c|c|c|c|}
\hline Road & \multicolumn{3}{|c|}{$\begin{array}{c}1 \\
\text { Emil Cioran str. }\end{array}$} & \multicolumn{3}{c|}{$\begin{array}{c}2 \\
\text { Unirii square } \\
\text { (descending) }\end{array}$} & $\begin{array}{c}3 \\
\text { Corneliu Coposu } \\
\text { Blvd. }\end{array}$ & \multicolumn{3}{c|}{$\begin{array}{c}4 \\
\text { Unirii square } \\
\text { (ascending) }\end{array}$} \\
\hline $\begin{array}{c}\text { Direction of } \\
\text { movement }\end{array}$ & $\leftarrow$ & $\uparrow$ & $\rightarrow$ & $\leftarrow$ & $\uparrow$ & $\rightarrow$ & $\leftarrow$ & $\uparrow$ & $\rightarrow$ & $\leftarrow$ & $\uparrow$ & $\rightarrow$ \\
\hline $\begin{array}{c}\text { Time range } \\
8: 00-8: 15\end{array}$ & 45.5 & 41 & 67 & 57 & 244 & 19.5 & 139 & 83.5 & 76 & 58.5 & 245 & 132.5 \\
\hline $12: 00-12: 15$ & 19 & 23.5 & 22 & 47.5 & 146 & 13 & 113 & 63 & 88.5 & 29 & 132 & 85 \\
\hline
\end{tabular}


The average $\mathrm{CO}$ pollution level recorded for the same time periods (again an arithmetic mean of the values recorded during the six days of the study), together with the maximal and minimal recorded values, is indicated in Table 2. For comparison reasons, the table also includes the value recorded by Borza et al. in 2012 [7].

Table 2. Carbon monoxide (CO) level determined in the crossroads area.

\begin{tabular}{|c|c|c|}
\hline Time period & $\begin{array}{c}\text { Average CO pollution } \\
\text { level }\left(\mathrm{mg} / \mathrm{m}^{3}\right)\end{array}$ & $\begin{array}{c}\text { Range of CO pollution } \\
\text { measurements }\left(\mathrm{mg} / \mathrm{m}^{3}\right)\end{array}$ \\
\hline $8: 00-8: 15(2017)$ & 11.19 & $10.3-11.5$ \\
\hline $12: 00-12: 15(2017)$ & 5.37 & $4.1-5.8$ \\
\hline $8: 00-8: 15(2012)$ & $10.44[7]$ & - \\
\hline $12: 00-12: 15(2012)$ & $4.64[7]$ & - \\
\hline
\end{tabular}

It can be noticed that the recorded CO pollution level for the time interval 8:00-8:15 is significantly higher than the legal threshold of $6 \mathrm{mg} / \mathrm{m}^{3}$, but also higher than the level recorded in 2012.

The noise levels recorded in the crossroads in parallel with the video recording of the traffic are indicated in Table 3. For comparison reasons, the table also includes the values recorded by Deac et al. in 2016 [10].

Table 3. Noise level determined in the crossroads area.

\begin{tabular}{|c|c|c|}
\hline Time period & $\begin{array}{c}\text { Average determined noise level } \\
(\mathrm{dB})\end{array}$ & $\begin{array}{c}\text { Range of determined noise } \\
\text { levels }(\mathrm{dB})\end{array}$ \\
\hline $8: 00-8: 15$ & 92.47 & $86.3-94.7$ \\
\hline $12: 00-12: 15$ & 72.33 & $68.7-74.3$ \\
\hline $8: 00-8: 15(2016)$ & $86.32[10]$ & - \\
\hline $12: 00-12: 15(2016)$ & $76.80[10]$ & - \\
\hline
\end{tabular}

As can be seen, there is a correspondence between the time of the maximal number of cars passing through the crossroads and the maximal noise level recording, which indicates that the solution for reducing the noise level in this crossroads resides with optimising the traffic in the area as a whole.

Both the $\mathrm{CO}$ and noise levels are very high in the morning hours, when people drive towards their workplaces, but the situation improves somewhat at midday, when there is less road traffic.

When comparing the data with those recorded in [6-10], there can be noticed an increase of both the number of vehicles recorded and of the pollution levels. This comes despite efforts by the city administration to tackle the problem by introducing, for example, roundabouts meant to ensure a better traffic flow.

\section{Conclusions}

The paper has attempted to present the current pollution and road traffic situation in the centre of Sibiu, based on measurements carried out in November 2017.

As has been shown, the current pollution levels are rather high, especially during the morning hours (peaks of $11.5 \mathrm{mg} \mathrm{CO} / \mathrm{m}^{3}$ and of $94.7 \mathrm{~dB}$, respectively), they having increased compared to studies carried out in the same area in 2012 and 2016.

While the city administration has attempted to improve the road traffic situation, it is obvious that in order to reduce the pollution levels, more action is needed, encompassing measures related to both the road geometry, the traffic lights system and the number of highly polluting cars allowed to drive through the city. 
In future, the authors intend to widen their researches in order to include more areas and more factors that can be taken into account.

\section{References}

1. Municipality of Sibiu, Interactive Map of Sibiu (Municipality of Sibiu, Sibiu, 2017)

2. M. Wiering, J. van Veenen, J. Vreeken, and A. Koopman, Intelligent traffic light control (Institute of Information and Computing Sciences, Utrecht, 2004)

3. J. Barceló, M. Delgado, G. Funes, D. García, J. Perarnau, A. Torday, SIAM News 40, 9 (2007)

4. L. Pan, E. Yao, Y. Yang, J. Environ. Manag. 183, 510 (2016)

5. C. Marino, A. Nucara, M. Pietrafesa, A. Pudano, Environ. Model. Assess. 21, 53 (2016)

6. SR 7348-2001, Road works. Equivalation of vehicles for determining the traffic capacity (ASRO, Bucharest, 2001)

7. S. Borza, V. Petrescu, Proceedings of ICEEM 2013, 343 (Vienna, 2013)

8. V. Petrescu, S. Borza, Environ. Eng. Manag. J. 12, 409 (2013)

9. M. Inta, A. Muntean, Proceedings of the Annual Session of Scientific Papers, XII, 177 (Oradea, 2013)

10. C. Deac, V. Petrescu, A. Gligor, MATEC Web Conf. 112, 09013 (2017)

11. C. Deac, M. Bibu, MATEC Web Conf. 121, 10002 (2017) 